DOI: $10.4274 /$ jarem.galenos.2021.46338

J Acad Res Med 2021;11(2):187-91

\title{
Hematological Parameters and Leukocyte Formulas in Predicting Celiac Disease in Children with Iron Deficiency Anemia
}

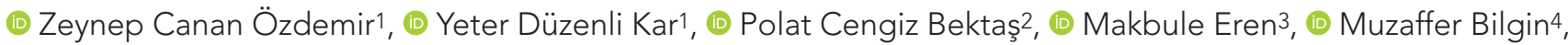 \\ (1) Özcan Bör 1
}

${ }^{1}$ Eskişehir Osmangazi University Faculty of Medicine, Department of Pediatrics, Division of Pediatric Hematology and Oncology, Eskişehir, Turkey ${ }^{2}$ Eskişehir Osmangazi University Faculty of Medicine, Department of Pediatrics, Eskişehir, Turkey

${ }^{3}$ istinye University Faculty of Medicine; Liv Hospital, Department of Pediatrics, Divison of Pediatric Gastroenterology Hepatology and Nutrition, İstanbul, Turkey

${ }^{4}$ Eskişehir Osmangazi University Faculty of Medicine, Department of Biostatistics, Eskişehir, Turkey

Cite this article as: Özdemir ZC, Düzenli Kar Y, Bektaş PC, Eren M, Bilgin M, Bör Ö. Hematological Parameters and Leukocyte Formulas in Predicting Celiac Disease in Children with Iron Deficiency Anemia. J Acad Res Med 2021;11(2):187-91

\begin{abstract}
Objective: Celiac disease (CD) is a systemic inflammatory disease associated with a number of hematological findings. The most common symptom other than the intestinal system is iron deficiency anemia (IDA). It is difficult to distinguish IDA that occurs in CD from nutritional IDA. In this study, the use of hematological parameters and leukocyte formulas, which are reported to be of diagnostic importance in inflammatory diseases, as a screening test in predicting $C D$ in children with IDA was investigated.

Methods: Forty-six children with CD and IDA, 46 children with nutritional IDA and 46 healthy children as a control group were included in the study. The patient files were examined retrospectively. The blood count parameters [Hemoglobin (Hb), mean corpuscular volume (MCV), mean corpuscular hemoglobin $(\mathrm{MCH})$, mean corpuscular hemoglobin concentration ( $\mathrm{MCHC}$ ), red cell distribution width (RDW), mean platelet volume (MPV), platelet distribution width (PDW), erythrocyte, leukocyte, neutrophil, lymphocyte, platelet count] of the patients before starting iron therapy were recorded. Leukocyte formulas [neutrophil/lymphocyte ratio (NLR), platelet/lymphocyte ratio (PLR), RDW/lymphocyte ratio (RLR)] were calculated.

Results: There was no difference between the patient and control groups in terms of age and gender distribution $(p>0.05) . \mathrm{Hb}, \mathrm{MCV}, \mathrm{MCH}, \mathrm{MCHC}$ values of CD+IDA and IDA groups were lower than the values of the control group ( $<<0.001$, for all), RDW, RLR, PLR values, and platelet count were higher than the values of the control group ( $p<0.001$ and $p<0.001 ; p<0.05$ and $p<0.01 ; p<0.05$ and $p<0.05 ; p<0.001$ and $p<0.05$, respectively). Leukocyte, neutrophil, lymphocyte, erythrocyte counts, MPV, PDW, NLR were found to be similar in the patient and control groups ( $p>0.05$ for all). There was no difference between the patient groups in terms of NLR, PLR, and RLR ( $p>0.05$ for all).

Conclusion: Our study showed that hematological parameters and leukocyte formulas are not useful in predicting CD in children with IDA.

Keywords: Child, celiac disease, iron deficiency anemia, hematological parameters, leukocyte formulas
\end{abstract}

ORCID IDs of the authors: Z.C.Ö. 0000-0002-9172-9627; Y.D.K. 0000-0003-2917-7750; P.C.B. 0000-0001-9757-5692; M.E. 0000-0002-7105-7165; M.B. 0000-0002-6072-6466; Ö.B. 0000-0002-1662-3259.

Sorumlu Yazar/Corresponding Author: Zeynep Canan Özdemir, E-mail: efecanan@yahoo.com
Geliş Tarihi/Received Date: 28.04.2021 Kabul Tarihi/Accepted Date: 15.06.2021

(C) Copyright 2021 by University of Health Sciences Turkey, Gaziosmanpaşa Training and Research Hospital. Available on-line at www.jarem.org 


\section{INTRODUCTION}

Celiac disease (CD) is an autoimmune disease of the small intestines triggered by a protein called gluten, found in dietary wheat, barley and rye in genetically susceptible individuals. It is an irreversible but treatable multifactorial disease (1). It is a common disease worldwide and its prevalence varies between 0.3-3\% (1). In pathogenesis; the conversion of glutamine-forming gliadin proteins to deamide peptides by the tissue transglutaminase enzyme in the intestinal submucosa plays a role in presenting these peptides, which are resistant to proteolysis, to CD4+ T-cells, which trigger an inflammatory reaction by binding to HLA-DQ2 and/or DQ8 molecules on the surface of antigen presenting cells in the lamina propria (2). Activation of these cells causes epithelial cell destruction and villous atrophy, probably mediated by nongluten-specific intraepithelial cytotoxic T-lymphocytes (3). Villous atrophy reduces the functional capacity of the intestine, resulting in malabsorption (4).

Iron deficiency anemia (IDA) is a well-known clinical form of CD. Evaluating patients with IDA without gastrointestinal symptoms as nutritional iron deficiency and trying to treat them with different iron preparations many times causes the diagnosis of celiac to be missed or delayed. Delay in diagnosis leads to increased treatment costs and causes patients to apply to the hospital unnecessarily many times. Red cell distribution width (RDW), neutrophil/lymphocyte ratio (NLR), platelet/lymphocyte ratio $(P L R), R D W /$ lymphocyte ratio $(R L R)$ were used as laboratory tests to help evaluate the diagnosis of $C D$, adherence to a gluten-free diet, and the severity of histopathological findings (5-8). Screening suspected celiac patients with the use of these frequently used laboratory indices and biomarkers before proceeding to the diagnostic steps in children with IDA may be an advantage.

In this study, the usability of hematological parameters, NLR, PLR and RLR formulas as a screening test in predicting CD in children with IDA was investigated.

\section{METHODS}

In this single-centered, cross-sectional, retrospective study, 57 children (IDA+CD group) who were followed up in the pediatric hematology and oncology outpatient clinic with IDA unresponsive to iron treatment and diagnosed with celiac by the pediatric gastroenterology department, 46 children diagnosed with nutritional IDA (IDA group) and 46 healthy children (control group) were included in this study. The diagnosis of $C D$ was made by clinical, serological, histopathological and genetic correlations.

The file records of all children included in the study were reviewed retrospectively. Hemoglobin $(\mathrm{Hb})$ at diagnosis, mean corpuscular volume (MCV), mean corpuscular hemoglobin (MCH), mean corpuscular hemoglobin concentration (MCHC), RDW, mean platelet volume (MPV), platelet distribution width (PDW), erythrocyte, leukocyte, neutrophil, lymphocyte, platelet count, ferritin level, transferrin saturation were recorded. Leukocyte formulas (NLR, PLR, RLR) were calculated. Laboratory parameters of the three groups were compared.

Anemia is defined as a $\mathrm{Hb}$ level below $11 \mathrm{~g} / \mathrm{dL}$ at the age of 6 months-5 years, $11.5 \mathrm{~g} / \mathrm{dL}$ at the age of $5-11$ years, and below 12 $\mathrm{g} / \mathrm{dL}$ at the age of $12-18$ years (9); iron deficiency was defined as a transferrin saturation of $<16 \%$ and a ferritin level of $<12 \mu \mathrm{g} / \mathrm{L}$ for children under the age of five, and $<15 \mu \mathrm{g} / \mathrm{L}$ for children over the age of five (10). The study was conducted in accordance with the principles of the Declaration of Helsinki and approval was obtained from the Eskişehir Osmangazi University Non-Invasive Clinical Research Ethics Committee on 06.11.2018 (decision no: 26).

\section{Exclusion Criteria}

In the CD and IDA group, a total of 11 patients, including 6 patients who had received iron therapy in the last three months before admission, and 5 patients with acute inflammation at the time of admission, were excluded from the study.

\section{Laboratory Analyzes}

All blood samples were collected after 8 hours of fasting. Complete blood count was performed freshly on an automated blood count analyzer (Beckman Coulter LH750, Kraemer Blud. Brea, CA, US). Blood samples taken into flat tubes for biochemical analysis were centrifuged at 1,500 $\mathrm{g}$ for 10 minutes, then their serum was separated and studied within the same day. Serum iron level was analyzed by photometric method (Cobas c502, Roche Diagnostics, Germany), ferritin level was analyzed by electrochemiluminescent method (Cobas E-602, Roche Diagnostics, Germany). Transferrin saturation was calculated with the formula serum ironx100/total iron binding capacity.

\section{Statistical Analysis}

SPSS 21 (IBM SPSS Corp.; Armonk, NY, USA) package program was used for statistical analysis of the data. Categorical data were expressed as frequency ( $n$ ) and percentage (\%). ShapiroWilk test was used to evaluate the normality distributions of the data. In the comparisons between groups, descriptive statistics were given as mean \pm standard deviation for data showing conformity with normal distribution, and median (25-75\%) for non-conforming data. One-Way ANOVA test was used for data conforming to normal distribution, and Kruskal-Wallis $\mathrm{H}$ test was used for variables not conforming to normal distribution. $\mathrm{P}<0.05$ was considered statistically significant.

\section{RESULTS}

A total of 138 children were included in the study. The patient group consisted of 92 (CD+IDA group: 46, IDA group: 46) and the control group consisted of 46 children. Number of girls/ boys in CD+DA group, IDA group, and control group were 25/21, 30/16, 24/22; median ages were 7 (3.7-10), 5.5 (2.8-13.2), 6 (4.8-10.2) years, respectively. There was no difference in age and gender distribution between the three groups ( $p>0.05$ for all). There was no difference between the three groups in terms 
of erythrocyte, leukocyte, neutrophil, lymphocyte count, MPV, PDW, NLR values ( $p>0.05$, for all). Hb, MCV, MCH, MCHC values of $C D+I D A$ group are lower than control group ( $p<0.001$, for all); RDW, PLR, RLR values and platelet count were higher than control group ( $p<0.001, p<0.05, p<0.05, p<0.001$, respectively). Hb, MCV, $\mathrm{MCH}$ values of the CD+IDA group were higher than the IDA group ( $p<0.05, p<0.001, p<0.001$, respectively) and lower than the control group ( $p<0.001$, for all). There was no difference between CD+IDA and IDA group in terms of NLR, PLR, and RLR ( $p>0.05$, for all). Transferrin saturation of CD+IDA group was higher than that of IDA group $(p<0.001)$ and ferritin level was similar $(p>0.05)$. The characteristics and laboratory parameters of the study groups are shown in Table 1.

\section{DISCUSSION}

IDA is the most common sign of $C D$ other than the intestinal system at the time of diagnosis $(11,12)$. It has been found that the frequency of IDA is between 6-82\% (13-17) and anemia is associated with greater disease severity and slower histological recovery in response to a gluten-free diet (18-20). For this reason, it is important to diagnose CD and start treatment in a short time in patients with CD accompanied by IDA.

It is known that RDW is an early indicator of iron deficiency and altered erythropoiesis in celiac patients (5). In two studies conducted in large patient series, it was reported that elevated RDW is a sensitive marker for the diagnosis of celiac in patients with strong clinical suspicion $(21,22)$. Our study showed that the RDW values of the CD+IDA group and the IDA group were similar, therefore, RDW could not be an indicator for the diagnosis of celiac in the presence of IDA.

The MPV is a marker of platelet function and activation and is affected by inflammation. The relationship between changes in MPV and celiac was first reported by O'Grady et al. (23). O'Grady et al. (23) and Purnak et al. (24) found that MPV in celiac patients was higher than the values in the control group, Demirezer Bolat et al. (25) reported that the MPV value was similar in the patient and control groups. In two studies, it has been reported that MPV is a useful biomarker to monitor adherence to the diet in the threemonth period after starting a gluten-free diet $(24,26)$. Demirezer Bolat et al. (25), on the other hand, reported that MPV is not useful either in the diagnosis of celiac or in monitoring adherence to diet (in a 1-year follow-up). In our study, we found that the MPV value in the CD+IDA group was similar to that of the IDA and control groups. Our results supported that MPV could not be used in the diagnosis of CD.

Apart from anemia in celiac patients, leukopenia, thrombocytopenia (27) and lymphopenia $(5,28)$ are other hematological abnormalities reported. It has been reported that low lymphocyte counts are

\section{Table 1. Characteristics and laboratory parameters of the patient and control groups}

\begin{tabular}{|c|c|c|c|c|}
\hline & $\begin{array}{l}\text { CD+IDA group } \\
(n=46)\end{array}$ & $\begin{array}{l}\text { IDA group } \\
(n=46)\end{array}$ & $\begin{array}{l}\text { Control group } \\
(n=46)\end{array}$ & $p$ \\
\hline Age (years) & $7(3.7-10)$ & $5.5(2.8-13.2)$ & $6(4.8-10.2)$ & $>0.05$ \\
\hline Gender (female/male) & $25 / 21$ & $30 / 16$ & $24 / 22$ & $>0.05$ \\
\hline $\mathrm{Hb}(\mathrm{g} / \mathrm{dL})$ & $10(8.5-10.4)$ & $9.5(8.3-10.6)$ & $12.7(12.0-13.1)$ & $<0.05^{a}<0.001^{b . c}$ \\
\hline $\mathrm{RBC}\left(\times 10^{6} / \mathrm{mm}^{3}\right)$ & $4.8(4.5-5.1)$ & $4.7(4.4-5.0)$ & $4.8(4.6-4.9)$ & $>0.05$ \\
\hline $\mathrm{MCHC}(\%)$ & $32(31-33.2)$ & $31.6(30.2-32.5)$ & $33.3(32.9-33.7)$ & $<0.001^{b . c}$ \\
\hline RDW (\%) & $17.9(15.8-19.7)$ & $19.5(12.8-14.7)$ & $13.3(12.8-14.7)$ & $<0.001^{b . c}$ \\
\hline Leukocyte count (x109/L) & $7.8(6.2-9.1)$ & $7.9(6.1-9.5)$ & $7.7(6.1-9.2)$ & $>0.05$ \\
\hline Neutrophil count $\left(\times 10^{9} / L\right)$ & $3.3(2.4-4.4)$ & $3.5(2.3-5.2)$ & $3.2(2.6-4.4)$ & $>0.05$ \\
\hline PDW (\%) & $16.6(16.3-17.4)$ & $16.6(16.4-17.1)$ & $16.4(16.2-16.7)$ & $>0.05$ \\
\hline NLR & $1.1(0.7-1.5)$ & $1.1(0.7-2.2)$ & $1.1(0.7-1.6)$ & $>0.05$ \\
\hline PLR & $111.3(82.1-154.4)$ & $117(71.6-158.8)$ & 85.9 (70.7-112.9) & $<0.05^{b . c}$ \\
\hline RLR & $5.7(4.2-7.4)$ & $6.6(3.8-8.7)$ & $4.5(3.4-5.5)$ & $<0.05^{b}<0.01^{c}$ \\
\hline Saturation (\%) & $8(4-8.9)$ & $5.1(3.9-7.1)$ & - & $<0.001$ \\
\hline Ferritin $(\mathrm{ng} / \mathrm{mL})$ & $6(4-8.9)$ & $6.9(4.2-8.7)$ & - & $>0.05$ \\
\hline
\end{tabular}


associated with celiac $(5,28,29)$. Studies have shown that the diagnostic power of NLR and PLR indices for celiac is high $(6,7)$, and the diagnostic power of RLR is better than NLR and PLR (5). Uslu ve ark. (8) have shown that the number of neutrophils in celiac patients compared to the control group at the time of diagnosis is high, the number of lymphocytes is low, NLR is high, the number of neutrophils and NLR values in patients who do not follow the diet after a year of gluten-free diet remain high, and the neutrophil number and NLR values in those who follow the diet are at the same level as the control group and they have also shown that NLR is useful for predicting patients who are not compliant with the gluten-free diet. It is thought that changes in the leukocyte formula in active $C D$ may be related to lymphocytic infiltration in the gastrointestinal tract and inflammation and cytokines that play a role in the pathogenesis of the disease (7). In our study, we showed that there was no difference between the patient groups and the control group in terms of leukocyte, neutrophil and lymphocyte count NLR values, RLR and PLR values were higher than the control group, and there was no difference between the CD+IDA group and IDA group in terms of the same parameters. The reason for the difference in RLR and PLR values was probably that the RDW and platelet values of the patient groups were significantly higher than the control group. High RDW and platelet values were also a finding that could be explained by iron deficiency. Therefore, we thought that this difference was not specific to $C D$.

$C D$, similar to many other autoimmune diseases, includes innate and acquired immune responses (30). Both experimental and clinical studies emphasize the importance of iron's effects on innate immunity (decreased bactericidal activity, respiratory burst in neutrophils) and cellular immunity (decreased lymphocyte proliferation and delayed hypersensitivity responses) $(31,32)$. Iron has important effects on the immune system due to its growth and differentiation stimulating properties, especially in lymphocytes (33). Iron is also important for monocyte/macrophage differentiation (34). Iron is also critical for enzymes involved in deoxyribonucleic acid synthesis and is an essential element for the proliferative phase of lymphocyte activation, and this phase can be weakened when iron is deficient (35). This may result in altered expression of cell surface markers and decreased T-cell proliferation (36). The fact that we did not find any change in hematological indices such as NLR and PLR in many inflammatory diseases in the CD+IDA group can be explained by the fact that iron deficiency affects the immune response and the response of the developing immune system to inflammatory events is different in children.

\section{Study Limitations}

The small number of patients and the retrospective nature of the study.

\section{CONCLUSION}

It was determined that the inflammatory response was different in children with $C D$ accompanied by IDA, and that the
NLR, RLR and PLR formulas did not have diagnostic power for the diagnosis of $C D$. There is a need for studies showing how humoral and cellular immunity are affected when these two conditions are combined, which cause changes in the immune system.

Ethics Committee Approval: The study was conducted in accordance with the principles of the Declaration of Helsinki and approval was obtained from the Eskişehir Osmangazi University Non-Invasive Clinical Research Ethics Committee on 06.11.2018 (decision no: 26).

Informed Consent: Retrospective study.

Peer-review: Externally and internally peer-reviewed.

Author Contributions: Concept - Z.C.Ö.; Design - Z.C.Ö.; Data Collection and/or Processing - Y.D.K., P.C.B.; Analysis and/or Interpretation - M.E., M.B., Ö.B.; Literature Search - Z.C.Ö., M.E., Ö.B.; Writing - Z.C.Ö.

Conflict of Interest: The authors have no conflict of interest to declare.

Financial Disclosure: The authors declared that this study has received no financial support.

\section{REFERENCES}

1. Guandalini S. The approach to Celiac Disease in children. Int J Pediatr Adolesc Med 2017; 43: 124-7.

2. Abadie V, Sollid LM, Barreiro LB, Jabri B. Integration of genetic and immunological insights into a model of celiac disease pathogenesis. Annu Rev Immunol 2011; 29: 493-525.

3. Setty M, Discepolo V, Abadie V, Kamhawi S, Mayassi T, Kent A, et al. Distinct and synergistic contributions of epithelial stress and adaptive immunity to functions of intraepithelial killer cells and active celiac disease. Gastroenterology 2015; 149: 681-91.e10.

4. Green PH, Cellier C. Celiac disease. N Engl J Med 200; 357: 1731-43.

5. Balaban DV, Popp A, Beata A, Vasilescu F, Jinga M. Diagnostic accuracy of red blood cell distribution width-to-lymphocyte ratio for celiac disease. Rev Română de Medicină de Lab 2018; 26; 45-50. (Romanian)

6. Sarikaya M, Dogan Z, Ergul B, Filik L. Neutrophil- to-lymphocyte ratio as a sensitive marker in diagnosis of celiac disease. Ann Gastroenterol 2014; 27: 431-2.

7. Sarikaya M, Dogan Z, Ergul B, Filik L. Platelet-to-lymphocyte ratio for early diagnosis of celiac disease. Indian J Gastroenterol 2015; 34: 182-3.

8. Uslu AU, Korkmaz S, Yonem O, Aydın B, Uncu T, Sekerci A, et al. Is there a link between neutrophil-lymphocyte ratio and patient compliance with gluten free diet in celiac disease? Gulhane Med J 2016; 58: 353-6.

9. WHO. Haemoglobin concentrations for the diagnosis of anaemia and assessment of severity. Geneva: World Health Organization; 2011. Available from: http://www.who.int/vmnis/indicators/haemoglobin.pdf

10. WHO, UNU, UNICEF. Iron deficiency anaemia: assessment, prevention and control, a guide for programme managers. Geneva, World Health Organization; 2001. Available from: https://www.who.int/nutrition/ publications/en/ida_assessment_prevention_control.pdf

11. Sansotta N, Amirikian K, Guandalini S, Jericho H. Celiac disease symptom resolution:effectiveness of the gluten-free diet. J Pediatric Gastroenterol Nutr 2018; 66; 48-52.

12. Ferrara M, Coppola L, Coppola A, Capozzi L. Iron deficiency in childhood and adolescence: retrospective review. Hematology 2006; 11; 183-6.

13. Berry N, Basha J, Varma N, Prasad KK, Vaiphei K, Dhaka N, et al. Anemia in celiac disease is multifactorial in etiology: A prospective study from India. JGH Open 2018; 2: 196-200.

14. Haapalahti M, Kulmala P, Karttunen TJ, Paajanen L, Laurila K, Mäki M, et al. Nutritional status in adolescents and young adults with screendetected celiac disease. J Pediatric Gastroenterol Nutr 2005; 40: 566-70.

15. Kuloglu Z, Kirsaclioglu CT, Kansu A, Ensari A, Girgin N. Celiac disease: presentation of 109 children. Yonsei Med J 2009; 50: 617-23.

16. Wessels MM, van Veen II, Vriezinga SL, Putter H, Rings EH, Mearin ML. Complementary serologic investigations in children with celiac disease is unnecessary during follow-up. J Pediatrics 2016; 169: 55-60.

17. Deora V, Aylward N, Sokoro A, El-Matary W. Serum Vitamins and Minerals at Diagnosis and Follow-up in Children with Celiac Disease. J Pediatric Gastroenterol Nutr 2017; 65; 185-9. 
18. Saukkonen J, Kaukinen K, Koivisto AM, Mäki M, Laurila K, Sievänen $H$, et al. Clinical characteristics and the dietary response in celiac disease patients presenting with or without anemia. J Clin Gastroenterol 2017; 51: 412-6.

19. Rajalahti T, Repo M, Kivelä L, Huhtala H, Mäki M, Kaukinen K, et al. Anemia in Pediatric Celiac Disease: Association with Clinical and Histological Features and response to gluten-free diet. J Pediatr Gastroenterol Nutr 2017; 64: e1-6. doi: 10.1097/MPG.00000000000001221.

20. Singh P, Arora S, Makharia GK. Presence of anemia in patients with celiac disease suggests more severe disease. Indian J Gastroenterol 2014; 33: 161-4.

21. Brusco G, Stefani MD, Corazza GR. Increased red cell distribution width and coeliac disease. Digest Liver Dis 2000; 32: 128-30.

22. Sategna Guidetti CS, Scaglione N, Martini S. Red cell distribution width as a marker of celiac disease: a prospective study. Eur J Gastroenterol Hepatol 2002; 14: 177-81.

23. O'Grady JG, Harding B, Stevens FM, Egan EL, McCarthy CF. Influence of splenectomy and the functional hyposplenism of coeliac disease on platelet count and volume. Scand J Haematol 1985; 34: 425-8.

24. Purnak T, Efe C, Yuksel O, Beyazit Y, Ozaslan E, Altiparmak E. Mean platelet volume could be a promising biomarker to monitor dietary compliance in celiac disease. Ups J Med Sci 2011; 116: 208-11.

25. Demirezer Bolat $A$, Köseoğlu H, Akın FE, Yürekli ÖT, Tahtacı M, Başaran $M$, et al. Can serum mean platelet volume be used as an inflammatory marker in patients with celiac disease? The Turkish Journal of Academic Gastroenterology 2018; 17: 62-5.

26. Ramachandran M, Agarwal A, Ravi M, Rajeshwari K, Lomash A, S. Mean platelet volume as short-term follow-up biomarker in children with celiac disease. Indian J Child Health 2017; 4: 515-7.
27. Fisgin T, Yarali N, Duru F, Usta B, Kara A. Hematologic manifestation of childhood celiac disease. Acta Haematol 2004; 111: 211-4.

28. Di Sabatino A, Bertrandi E, Casadei Maldini M, Pennese F, Proietti F, Corazza GR. Phenotyping of peripheral blood lymphocytes in adult coeliac disease. Immunology 1998; 95: 572-6.

29. Di Sabatino A, D'Alò S, Millimaggi D, Ciccocioppo R, Parroni R, Sciarra $G$, et al. Apoptosis and peripheral blood lymphocyte depletion in coeliac disease. Immunology 2001; 103: 435-40.

30. Stepniak D, Koning F. Celiac disease-sandwiched between innate and adaptive immunity. Hum Immunol 2006; 67: 460-8.

31. Beard JL. Iron biology in immune function, muscle metabolism and neuronal functioning. J Nutr 2001; 131: 568S-79S.

32. Ekiz C, Agaoglu L, Karakas Z, Gurel N, Yalcin I. The effect of iron deficiency anemia on the function of the immune system. Hematol J 2005; 5: 579-83.

33. Weiss G. Iron, infection and anemia a classical triad. Wein Klin Wochenschr 2000; 114: 357-67.

34. Collins HL. The role of iron in infections with intracellular bacteria. Immunol Lett 2003; 133: 336S-40S.

35. Brock JH, Mulero V. Cellular and molecular aspects of iron and immune function. Proc Nutr Soc 2000; 59: 537-40.

36. Kuvibidila SR, Porretta C. Iron deficiency and in vitro iron chelation reduce the expression of cluster of differentiation molecule CD28 but not CD3 receptors on murine thymocytes and spleen cells. Br J Nutr 2003; 90: $179-89$. 